\title{
Is it desirable, necessary and possible to perform research using case studies?
}

\author{
¿Se quiere, se debe y se puede investigar con \\ estudios de casos?
}

\author{
Oskar Villarreal Larrinaga ${ }^{1}$ \\ Universidad del País Vasco UPV/EHU (España)
}

Recibido el 18 de diciembre de 2014, aceptado el 3 de diciembre de 2015

Publicado online el 4 de mayo de 2016

$\mathrm{N}^{\mathrm{o}}$ de clasificación JEL: B49, M19

DOI: $10.5295 / \mathrm{cdg} .1405160 \mathrm{v}$

\begin{abstract}
:
Articles on the research methodology to be used in Business Economics generally address the key aspects involved in designing the research, such as procedure, techniques of evidence gathering and analysis and associated tests of rigor and quality. However, researchers involved in some of the more "uncommon" scientific research methodologies (albeit necessary in social science) such as case studies have some rather more existential questions (Why and for what purpose should one use case studies in research?). They need answers to these questions if they are to overcome the technical problems of the research process and, above all, the prejudice against such methodologies encountered amongst the scientific community. As well as addressing the key aspects of research design, this paper sets out to discuss the raison d'être of case study as a scientific research methodology. In doing so, it will use three principal questions in order to approach the discussion from a different perspective. These three questions are: is it desirable, is it necessary and is it possible to perform research using case studies? In answering these questions, it is hoped to provide robust arguments that will justify the use of this methodology, as well as substantial elements for building appropriate and rigorous designs for scientifically-based and focused case study research.
\end{abstract}

\section{Keywords:}

Case study, research methodology, business economics.

\section{Resumen:}

Los artículos metodológicos sobre investigación de la Economía de la Empresa afrontan, generalmente, los aspectos clave del diseño de la investigación, esto es, el procedimiento, las técnicas de recogida de evidencia y de análisis y las pruebas de rigor y calidad asociadas a aquel. No obstante, los investigadores que se enfrentan a metodologías de investigación científica "no habituales”, aunque necesarias en ciencias sociales, como es el estudio de casos requieren la respuesta de ciertas cuestiones de naturaleza más existencial (¿Por qué? y ¿Para qué investigar con casos?) si pretenden superar con cierta holgura los problemas técnicos del proceso de investigación y, especialmente, los prejuicios de parte de la comunidad científica contra estas metodologías. Este trabajo pretende añadir, además de los aspectos clave del diseño de la investigación, una reflexión previa sobre

1 Instituto de Economía Aplicada a la Empresa (IEAE). Facultad CC. Económicas y Empresariales, Avda. Lehendakari Agirre 83, 48015 Bilbao (España). oskar.villarreal@ehu.eus 
Is it desirable, necessary and possible to perform research using case studies?

la "razón de ser" del estudio de casos como metodología de investigación científica a partir de tres cuestiones principales que van a permitir estructurar con diferente prisma dicha reflexión. Estas tres cuestiones son: ¿se quiere, se debe y se puede investigar con estudios de casos? A través de sus respectivas respuestas se pretende dar argumentos robustos que justifiquen su utilización y elementos sustanciales para la construcción de diseños adecuados y rigurosos para una investigación con casos con sentido y dirección científica.

\section{Palabras clave:}

Estudio de casos, metodología de investigación, economía de la empresa. 


\section{INTRODUCTION}

Case study research is a methodology based on empirical enquiry (Yin 1989 and 2014; Eisenhardt 1989) with essentially qualitative techniques from real contexts, in which multiple sources of evidence are used with an essentially inductive -and partially deductive- scientific approach (Yin 2014). Yin (1989, p. 23), defines a case study as "empirical inquiry that investigates a contemporary phenomenon within its real-life context; when the boundaries between phenomenon and context are not clearly evident; and in which multiple sources of evidence are used ". Clearly, these are common circumstances in the field of business economics (Arias 2003).

Case-study research was first used in business studies at the beginning of the twentieth century in American business schools (with Harvard at the forefront) as a methodology for teaching and researching business phenomena and general management (Stoeker 1991). The baton was subsequently taken up by the University of Chicago (Hamel et al. 1993). These developments, however, generated very little in the way of academic theory and debate (Rumelt et al. 1994). The effectiveness of case study as a research tool was greatly limited and the method was widely questioned, losing favour in the scientific community to more objective, reliable, valid and representative quantitative methods, which were closer in approach to the experimental sciences.

However, such quantitative methods also encountered serious limitations for studying complex and changing situations such as those found in business, and the result was a renewed debate in the 1960s in favour of qualitative methods in both the Rand Corporation (Helmer and Rescher 1959; Landeta 1999) and in the second Chicago School, where it crystallised into what became known as the "new" or second Chicago school, headed by Glasser and Strauss (1967), authors of the Grounded Theory, where the techniques and procedures of analysis are designed to bring some scientific precision and rigour to the research process (Strauss 1987).

Against this backdrop, a series of important methodological contributions leading to contemporary case study research were made in the 1980s. This movement was spearheaded by Yin (1989, 1993, 1998 and 2014), together with Eisenhardt (1989, 1991), with work continuing under Patton (1990), Stoeker (1991), Hamel (1992), Hamel et al. (1993), Stake (1994) and Maxwell (1996, 1998). Some valuable contributions have been made by a number of Hispanic researchers: Ruiz (1996), Rialp (1998), Sarabia (1999), Bonache (1999), Fong (2002), Arias (2003), Oltra (2003), Rialp et al. (2005), Cepeda and Martin (2005), Cepeda (2006), Vaillant et al. (2006), Villarreal (2007, 2008), Villarreal and Landeta (2010) and Villarreal and Calvo (2015).

This fresh drive has once again placed case study among the catalogue of available scientific methods, and while it is less frequently used than other, quantitative, methods, case study research is regularly published in the most prestigious management journals. However, it still encounters relatively low acceptance among a certain section of the scientific community and it cannot be said to be a widely used scientific methodology.

This paper will concentrate on this aspect. Still today and despite the volume and quality of research performed using case studies, some researchers encounter serious difficulties in their academic environments in using this research methodology. 
The aim of this work is to provide a robust argument to justify the use of case studies as a research methodology, as well as setting out the substantial elements for constructing a suitable design for rigorous research. The arguments will be structured using the questions posed in the title "Is it desirable, necessary and possible to perform research using case studies?"

Whatever methodology is used, any research must be built on certain premises, which provide it with its grounding and sustenance and allow the enquiry to be brought to a successful conclusion. These basic elements are a) motivation, which ties in with the researcher's own personal interest in the subject matter and is associated with the professional requirements of an academic university career; b) the rigor and quality that may be demanded of any scientific research; and c) an appraisal of the scientific merits required by the academic system.

\section{IS IT DESIRABLE TO PERFORM RESEARCH USING CASE STUDIES? CHOICE OF RESEARCH METHODOLOGY}

Undoubtedly the most personal of the three question is "is it desirable to perform research using case studies?". And yet it is also probably the most relevant, because it relates to the aims of the researcher and the research itself. The decision to use case study research means choosing to answer certain questions (Why? and How?) over others (What? and How much?). Wanting to use case study research means renouncing the precision of exact data and enjoying the ambiguity of reality. Wanting to use case study research does not mean rejecting or accepting null hypotheses, but contrasting rival judgements and theories that are fulfilled in different contexts. Wanting to use case study research therefore means forgetting about the blacks and whites (accept or reject) and opting instead for the full palette of colours. This is the reality faced by the researcher; a hybrid one, with a multitude of shades and nuances.

Here it is relevant to establish the relationship between the aims of the research and the strategy or methodologies. Extending this relationship by introducing the researcher's control over the object of study, and the degree of focus on contemporary or historical realities, Yin (1989) discusses the choice of the most suitable method for carrying out the research, as shown in Table 1, which shows the criteria considered appropriate for choosing a research strategy:

Yin (1989) argues that the alternatives (though not the rivals) to case study method are experiments, surveys, histories, and the analysis of archival information. Each strategy has peculiar advantages and disadvantages, depending on three conditions: 1) the type of research question; 2) the control an investigator has over actual behavioural events; and 3) the focus on contemporary as opposed to historical phenomena.

Case studies are the preferred strategy when "how" or "why" questions are being posed, when the investigator has little control over events, and when the focus is on a contemporary phenomenon within some real-life context. Such methodology is therefore particularly suitable in business economics research, which frequently strives to answer "how" and "why" questions, with no control over facts or behaviour and a focus on contemporary phenomena (Arias 2003). 
Table 1

Relevant situations for conditioning methodological research strategies

\begin{tabular}{|c|c|c|c|}
\hline Strategy & $\begin{array}{c}\text { Form of question to } \\
\text { be researched }\end{array}$ & $\begin{array}{c}\text { Control over facts } \\
\text { or behaviour }\end{array}$ & $\begin{array}{c}\text { Emphasis on historical or } \\
\text { contemporary events }\end{array}$ \\
\hline Experiment & How, Why & Yes & Contemporary \\
\hline Survey & $\begin{array}{c}\text { Who, What, Where, } \\
\text { How Many, When }\end{array}$ & No & Contemporary \\
\hline Analysis of archives & $\begin{array}{c}\text { Who, What, Where, } \\
\text { How Many, When }\end{array}$ & No & Historical \\
\hline Historical analysis & How, Why & No & Contemporary \\
\hline Case study & How, Why & No & \\
\hline
\end{tabular}

Source: Yin (1989).

The characteristics of this methodology, and the type of questions that can be answered by using it, make it suitable for addressing issues such as (Yin 1989):

1) Explaining causal relations that are too complex for the research strategies using surveys or experiments.

2) Describing the real context in which an event or intervention has taken place.

3) Assessing the results of an intervention.

4) Exploring situations in which the intervention assessed does not have a clear and singular result.

It is also particularly suitable for analysing processes of longitudinal change (Eisenhardt 1989) and for gaining a holistic-as opposed to reductionist-perspective of a phenomenon (Gummesson 1991). This method is therefore highly recommended when the phenomenon to be studied cannot be understood outside its natural context or setting, when a large number of elements need to be taken into consideration and when a large number of observations are required (Johnston et al. 1999), in other words, when the purpose is to understand a real phenomenon taking into account all the variables that have a bearing on it (McCutcheon and Meredith 1993).

Miles and Huberman (1994) argue that this qualitative research is characterised by prolonged contact for the purpose of study, the researcher's search for a holistic vision, the attempt to capture the data "from inside" based on the perceptions of local agents, the possibility of making multiple interpretations of the data obtained, and the non-existence of standardised instrumental mechanisms.

Ultimately, all of these arguments are related to the research aims and their usefulness to the research disciplines. The first conclusion, therefore, is that one should choose case study research because it is appropriate and useful for investigating the social sciences, including business economics. 


\section{IS IT NECESSARY TO PERFORM RESEARCH USING CASE STUDIES? THE NEED TO PERFORM RESEARCH USING CASE STUDIES}

The second questions raised, is there a need to perform research using case studies? widens the scope of the argument. Aspects that need to be addressed include the disciplinary framework, the subject matter, the object of study, the unit of analysis and -once againthe aim of the research. All of these aspects suggest the need to consider alternatives to the more "common" research approaches. One of these alternatives is case study research.

Here it is worth noting that although the social sciences in general (and economic and business science in particular) are not exact or deterministic sciences, they are nonetheless researched as if they were. Indeed, one can see a certain analogy with the field of physics. Unlike social sciences, this scientific discipline has always been considered exact and deterministic; nonetheless for some time the uncertainty principle has been accepted (by Max Planck, Einstein, Dirac, Bohr, etc.) in quantum mechanics, one of the main branches of physics. We might argue that business economics is also a "quantum" science, and therefore uncertain. Conditioned as they are by the determinism of classical physics, scientists from other branches have often had difficulty accepting the uncertainty principle for cultural and educational reasons. Similarly, economists are all too often conditioned by the determinism of the classic form of economic research.

And so we look for universal theses and general theories, unquestioningly accepting that a hypothesis must be either accepted or rejected. And yet we barely lend any importance to the context, which can have such a bearing on the phenomena studied that one theory may explain them in certain contexts and another in others. The reality is ambiguous and uncertain and case study research is a suitable methodology for this approach.

Among the purposes for which qualitative studies might be valid is an understanding of the processes by which actions and events take place (Maxwell 1998). Qualitative research allows us to address broad questions of science, as opposed to methods centring on a precise analysis of specific issues. It therefore enables us to answer more questions less precisely (Beer 1988).

At the same time, a general dynamic of change in the business world has led to a questioning of traditional solutions and theories, spurring the science of business economics towards a progressive search for new models that are better suited to the new circumstances under study (Applegate 1994). New and different explanatory models cannot always be created using methodology based on an appraisal and comparison of hypotheses within a validated existing theoretical framework. As a result new methodologies have emerged, enabling new theories to be generated (Arias 2003). Case study offers a methodology of research that needs to be taken into account by a science whose purpose is to satisfy the most pressing needs for a greater understanding of the society it serves.

Case study allows phenomena to be analysed in a real context, using many different quantitative and/or qualitative sources of evidence simultaneously. It involves a large quantity of subjective information, does not allow statistical inference to be applied and is greatly influenced by the researcher's subjective judgement in selecting and interpreting the information. As a qualitative research methodology, therefore, the main weaknesses of case study according to its detractors are the limitations on the reliability of its results and generalisation of its conclusions (Martínez 2006), which bring it into conflict with more 
traditional scientific norms. To some extent this has marginalised (or even excluded) it as a scientific methodology of empirical research, in comparison with other more quantitative and objective forms of enquiry. However, provided it used with rigour and care, applying procedures that will increase its reliability and validity, it has a valuable contribution to make in advancing our understanding of certain complex phenomena.

For some time now, a great number of authors seeking a more practical and applied vision of the science have championed the use of subjective information and research techniques in scientific practise. However, continuous work is required to improve the design and application of such methodologies.

One key issue that should concern researchers in this area is the quality of the information used in their investigations. Quantitative methodologies present problems unrelated to their sample size, which might make the use of such quantitative analysis inadvisable for this type of research (Fong 2002).

Qualitative methodology provides relevant perspectives for research in the field of social science, including business economics. However, its potential has traditionally been underestimated in comparison to other (quantitative) techniques. This is essentially due to a lack of understanding of its application among both academics and executives. Nonetheless, particularly in the field of business management, the use of qualitative methods offers great potential for increasing our knowledge of organisational behaviour. Studies of companies should essentially focus on understanding their actions and assisting them, offering intuition and recommendations that will help resolve their specific problems and/or those of their industry. It is therefore advisable to develop more essentially an essentially applied style of research (Rialp 1998).

If this is the guiding light of these applied sciences, it would be unforgivable, to dispense -out of some misguided objectivity or appeal to "scientificness"- with subjective information provided by individuals ("experts"), who can contribute effectively to this administrative efficiency in achieving the company's goals (Landeta 1999).

Resorting to subjective judgement -i.e., what the experts say- does not mean looking into a crystal ball or seeking advice from a fortune teller or futurologist; it does not involve a rejection of scientific methodology. On the contrary, the purpose is to operate scientifically with these experts, developing methods and techniques that will make it possible to obtain and use the subjective information they provide in an explicit, reasoned and systematic way, ensuring its effectiveness and the highest possible degree of objectivity (Helmer and Rescher 1959). In short, the purpose is to view scientific methodology in less restricted terms (Landeta 1999).

It is necessary to find the best possible way of dealing with uncertainty given the scientific possibilities of our age. Decision-making will increasingly require the subjective knowledge of good experts. The past is projected ever less appropriately on the future and statistics only really guide us to the present (Kaufmann and Gil Aluja 1991).

From this perspective, academics can contribute to improving the society they are studying. Achieving the three main challenges of this field (access to information from reality, preunderstanding and understanding concurrent with the study programme and a high degree of quality in the work (Gummesson 1991)) does not solely involve the use of statistical techniques (quantitative methodology). Such techniques should only be applied where they are really useful (Rialp 1998). 
It is worth noting that certain methodologies considered qualitative (particularly case study) may also be quantitative. The same case study may gather and analyse both qualitative and quantitative information (Yin 1998). Use of this tool allows for complementarity between the two (Yin 1993; Céspedes and Sánchez 1996; Bonache 1999). In reality, however, qualitative methods tend to predominate (Stake 1994).

Either of the research methods has the same potential to contribute to development of the science if it is applied correctly. One might see the two methodologies (quantitative and qualitative) as alternative strategies for approaching reality and that their relative suitability depends on factors unrelated to their scientific capacity. Case studies, surveys, laboratory experiments and all the other methods of empirical research offer different possible strategies (Yin 1989). These strategies are chosen according to their suitability for achieving the desired goal.

\section{IS IT POSSIBLE TO PERFORM RESEARCH USING CASE STUDIES? COP- ING WITH THE METHODOLOGICAL WEAKNESSES}

Having shown that case study research is both desirable and necessary, we shall now turn to the third of our questions: Is it possible to research with case studies? We shall address this issue by looking at the principal criticisms levelled against case study methodo$\operatorname{logy}$ in the scientific literature. We shall then establish a design and procedures to eliminate these weaknesses or at least reduce hem to acceptable levels, with investigative rigor and quality as an essential prerequisite.

As already discussed, case study research offers certain advantages over other methodologies which make it useful for certain aims and in certain circumstances; however, it is also true that there are certain inherent weaknesses in its methodology that limit its scientific potential. In recent decades, valuable contributions from a number of researchers have helped reduce the negative impact of these weaknesses and endow this increasingly necessary methodology with greater quality and scientific rigour. Nonetheless, new research is still needed to help further augment its reliability and validity and to respond to reservations as to its scientific use, in order to provide a new and generally accepted research methodology for business economics. With this aim in mind, we will now propose a methodological design, built on contributions from previous researchers and our own experience.

Behind the reservations outlined in the previous paragraph lie certain weaknesses inherent to case study research and it these that have attracted most criticism of the methodology:

The first criticism is that the results obtained are inconsistent (Arias 2003) and biased (Bonache 1999; Arias 2003). "Researcher bias" stems from the fact that it is the researcher who determines the phenomenon to be studied, chooses the theoretical framework, weighs up the relevance of the different sources, and analyses the causal relationship between the facts. All of these factors distance him from the ideal of the objective researcher who tries to remove any personal stamp from the way the data is arranged; consequently, this type of study is accused of being non-objective and unreliable (Bonache 1999).

Maxwell (1998) breaks this criticism down into two aspects which he views as the principal threats to the validity of qualitative research: one is the bias introduced by the 
researcher during data gathering and analysis; and the other is the reactivity or its influence on the participants in the study. Gummesson (1991) and Hamel et al. (1993) link this criticism to the possible lack of rigor in the gathering, construction and analysis of the empirical evidence provided. This is to a large extent caused by the supposed subjectivity of the researchers and the informants on whom they depend for an understanding of the case. However, various studies show that inconsistency and bias are just as likely to occur in conducting experiments (Rosenthal 1966), designing questionnaires for surveys (Arias 2003) and performing historical analysis (Gottschalk 1968).

In this regard, the criticism is based on an erroneous premise; that subjectivity is a negative quality in a researcher. Can researchers be entirely objective? Is it really desirable for them to be so? All researchers have received a specific training; they carry their own personal scientific baggage and have their own individual talents. Together, these factors combine to make every researcher "subjective"; it is a quality which cannot -and should not- be eliminated. What is at issue is not the researchers' subjectivity, but their "honesty". And certainly, one may be honest or dishonest whatever the research methodology.

The second criticism (and probably the most serious) relates to the problem of generalising the results obtained from the study of a -necessarily- limited number of cases (Rialp 1998), in that a single case or set of cases cannot represent a significant sample (Bonache 1999; Arias 2003). This criticism is levelled by Gummesson (1991) and Hamel et al. (1993), based on three arguments: lack of statistical validity; usefulness in generating hypotheses, but not in testing them out; and lack of representativeness of the phenomenon under study, preventing generalisations being drawn from the case studies.

The possible problems posed by inductive methods may be partly resolved using Popperian falsificationism (Popper 1962; Lakatos 1983). However, perhaps the best reply to this criticism has come from Yin (1989, 1998 and 2014) who points out that depending on the purpose of the research, this method may be judged to be suitable when it pursues the enlightenment, representation, expansion or generalisation of a theoretical framework (analytical generalisation through replication logic), and not the mere listing of frequencies of a sample or group of subjects as in surveys and experiments (statistical generalisation).

Thus the results of even one case study can be generalised to others with similar theoretical conditions. Hence the importance of context. Multiple case studies reinforce these analytical generalisations by being designed either to produce corroborative evidence based on two or more cases (literal replication) or alternatively, to allow for different theoretical conditions that have opposing results, albeit for predictable reasons (theoretical replication).

Case study research therefore contrasts different contexts, and may go so far as to confirm opposing theories without rejecting either hypothesis. Certainly, this is a form of research that involves a "science of theoretical integration".

Rialp (1998) adds an important nuance, stating that any generalisation from a case study should be approached in a different way to that used with statistical samples. Its representativeness lies not only in the purpose and design of the research, but also in the methodological qualities of the case chosen, based on the results of analysis. The principal dynamic of quantitative studies, which are based on a large number of observations, consists of determining "how much" or "how often" a given event occurs. In contrast, an in-depth analysis of cases -a more qualitative approach- seeks to understand the process 
by which certain phenomena take place. As well as making it possible adequately to capture the heterogeneity and range of variation existing in a given population, the theoretical or purpose-built selection of qualitative research (as opposed to probabilistic or random sampling) makes it possible to deliberately select cases that are considered critical for assessing an existing or developing theory. This allows particular comparisons to be established to identify possible similarities and differences between the different units of analysis, especially in multiple case studies (Gummesson 1991; Maxwell 1998). Moreover, these multiple case-study techniques offer generalizable results (Arias 2003).

Gummesson (1991) even went so far as to question the very point of generalisation in the social context, arguing that knowledge in this area occurs when the researcher knows how to deal with specific situations (generalisation v. particularisation). The issue at stake in the generalisation of qualitative studies (including, therefore, case study) is not whether a probabilistic sample can be taken from a broader population to whom the results can then be extended, but whether a theory can be developed that can then be transferred to other cases. Some authors therefore prefer to talk about "transferability" rather than "generalisation", in qualitative research (Maxwell 1998). This issue is related to the search for universal theses and generalised theories discussed in the previous section. Is this a realistic goal in social science and business economics?

A third criticism levelled against case study research is the vast amount of information it generates, which may too great to systematise. This will depend on the researchers' capacity and methodology and their skill in converting an enormous amount of information in different formats into synthetic information that can be compared to the model proposed in the research (Arias 2003). Gummesson (1991) and Hamel et al. (1993) link this criticism to an excessive trust in the researcher's common sense.

In this regard, Yin (2014) says that one of the traditional criticisms of case studies is that they take too long and result in massive, unreadable documents. This complaint may be appropriate, he says, given the way case studies have been done in the past, but this is not necessarily the way case studies should be done now or in the future, when the lengthy narrative can be avoided altogether He argues that the belief that case studies must necessarily take a long time incorrectly confuses the case study method with a specific method of data collection such as ethnography or participant observation, whose precursors were Boas and Malinowski (Angrosino 2012). These methods require long periods of time in the "field" and emphasize detailed, observational evidence. In contrast, case study does not depend exclusively on this method of data collection.

This complaint is directly linked to the reliability of the research and is, probably the fairest and most accurate of all the criticisms, although not the one most forcefully used in current criticism. It is true that case study researchers do not generally make available to the scientific community all the information they have used in reaching their conclusions. This has implications for reliability, which presupposes that any other researcher or reader should be able to reach the same conclusions (or at least, understand how they have been reached). Nonetheless, we consider that the information and communication technology available today make it possible take a much stricter and more rigorous approach to this issue. We propose that the information should be made available on publicly-accessible computer platforms to be verified by anyone so wishing, while respecting previously-agreed ethical issues of confidentiality. 
As discussed, despite these criticisms, case study methodology is increasingly being used in social science because there are questions that need to be tackled using a criterion of practical applicability and social interest with the most scientific methodologies possible, even in cases in which classical quantitative methodologies cannot be used. As an applied methodology, case study is increasingly being accepted as an instrument of scientific research in business management, especially since it has been seen that access to first-hand information and/or an understanding of the decision-making processes, implementation and change in organisations requires a type of analysis that is impossible to achieve in sufficient depth through large numbers of observations (Rialp 1998).

Helmer (1983), one of the fathers of another qualitative research method-the Delphi Method-suggested three areas of action for improving the scientific nature of this kind of methodology: a) improving the way the most appropriate sources of information are selected by establishing selection criteria, b) facilitating effective transmission of the required information, improving data-gathering techniques and the performance of informants and c) developing and improving methodologies of action that will integrate the information and ensure the quality of the conclusions drawn.

Our methodological research is intended to go some way to achieving these goals. Its primary aim is to propose a methodological design for using case studies in scientific research, based on a review and integration of contributions from many other authors and on our own experience in the three areas of action we have outlined. We also want to defend the validity of using case study as a methodology of scientific research for explaining new business phenomena and increasing scientific understanding of the business reality when suitable conditions arise and the right design is used and applied rigorously.

\section{PROPOSED METHODOLOGICAL DESIGN FOR CASE STUDY}

The figure below shows our proposed methodology for empirical research in business economics using case studies which is applicable to the social sciences in general (Villarreal 2007; Villarreal and Landeta 2010). This design has been drawn up using the most relevant contributions taken from a review of the literature, augmented by our own experience and applied with satisfactory results in contemporary multiple case studies of a holistic nature (Villarreal 2007 and 2011), studying cases on internationalisation of companies and in single case studies, also of a holistic nature (Villarreal 2008; Villarreal and Calvo 2015) with subject matters that also included innovation. 
Figure 1

\section{Proposed Methodological Design for Case Study}

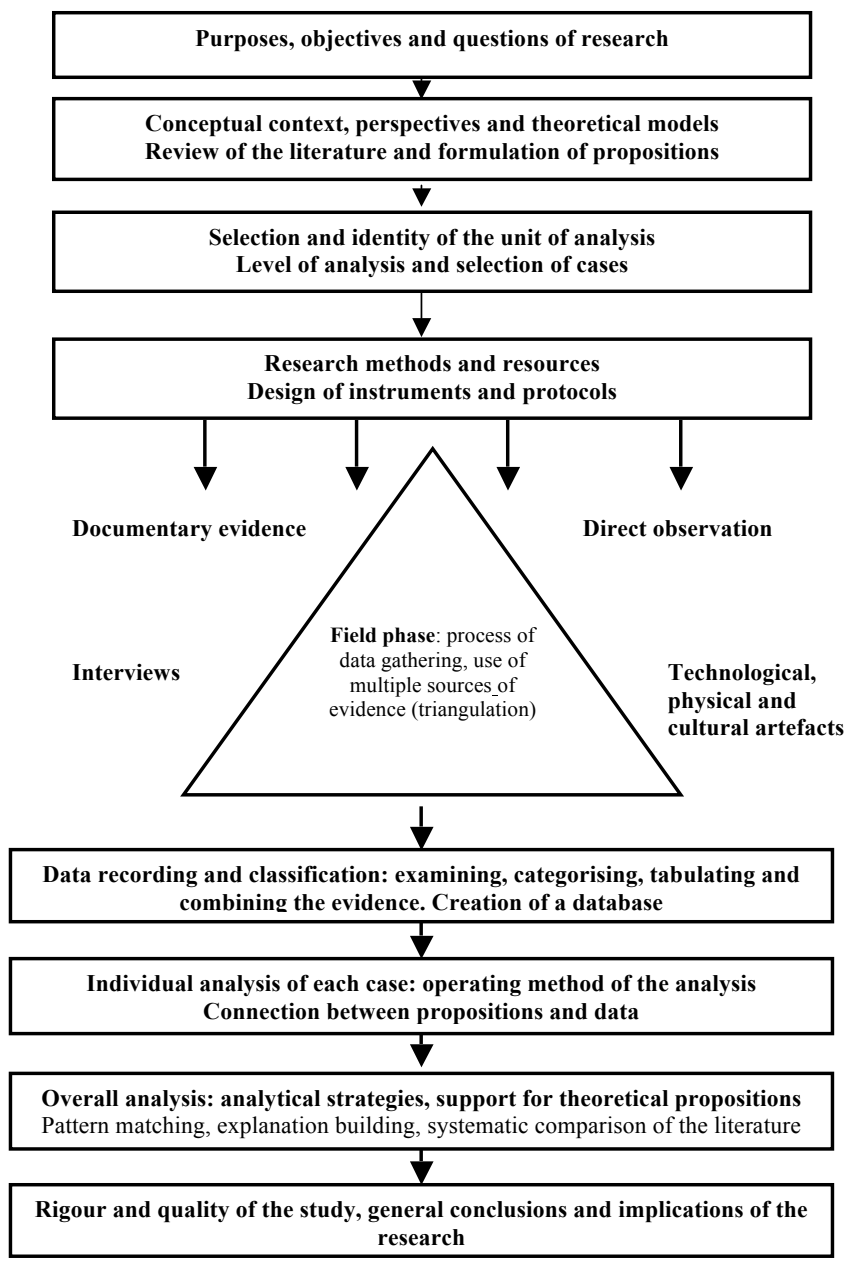

Source: Own elaboration based on Eisenhardt (1989), Yin (1989, 1998), Maxwell (1996, 1998), Rialp (1998), Shaw (1999), Fong (2002), Rialp et al. (2005).

We shall now describe the nine phases of the proposed design:

\subsection{Purpose, objectives and questions of research}

As a methodology of empirical research, case study requires researchers to have a clear idea from the outset of their ultimate aims, their purpose in obtaining and interpreting the large quantities of information, the object of the study and what they wish to know about 
the organisations to be analysed (questions of general research). The study may serve to describe a phenomenon within real organisations-to explore a situation about which there is no well-defined theoretical framework; for the purposes of preparing other more precise research; to explain why certain phenomena occur, acting as the basis for developing new theories (Yin 1989, 1993, 1998); to illustrate good practice (Bonache 1999) or to validate theoretical proposals (Yin 1989). In all cases, these objectives must be clearly determined before the research begins.

\subsection{Conceptual context, perspectives and theoretical models. Review of the litera- ture and formulation of propositions}

As with any research, an empirical work must be undertaken from the frontier of knowledge already reached by the scientific community. Before addressing the phenomenon under study in a real company setting, we therefore need to begin with reference literature and/or prior research (Yin 1989, 2014; Cooper 1984; Maxwell 1996, 1998; Fong 2002), specifying and defining key concepts; determining what is not known and what we wish to know through this research, and knowing and selecting those existing theoretical models which, a priori, might best help us apprehend and explain that complex and open situation and, thus orient the study. Based on these models, on can derive theoretical propositions formulated hypothetically, together with their corresponding rival hypotheses or theories (alternative explanations) which will reinforce both the design of the research and the theoretical reasoning and support for it (Rialp 1998). It is recommended that rival hypotheses be formulated, establishing an alternative theory that seeks to explain the same result from a different theoretical substratum.

\subsection{Selection and identity of the unit of analysis. Level of analysis and selection of cases}

The next step is to make a suitable definition of the unit of analysis. This involves defining the "case" itself (Yin 1989, 2014). This should help trace the borders of the study as far as possible. However, it is sometimes very difficult to separate a given phenomenon from the context in which it occurs (Rialp 1998). The unit of analysis relates back to the fundamental problem of determining the type of case. As a general rule of thumb, the definition of the unit of analysis, and by extension the type of case, will be related to the way in which the question of initial research has been defined. If there have been previous studies, they will provide some criterion of choice that will enable a comparison of the results (Yin 1989).

Once the unit of analysis has been defined, the case(s) to be studied can be selected on the basis of theoretical -not statistical-sampling. The researcher tries to select cases that offer the greatest opportunity for learning (Stake 1994), and which will enable analytical (not statistical) generalisation of the results (Ragin and Becker 1992; Easton 1994; Yin 2014). The purpose is to determine the core around which any questions raised are to be studied; what is going to be analysed (a single company, a group of companies, relations between various organisations, etc.) (Johnston et al. 1999). 
Case studies may have several units of analysis, when the researcher wants to assess each aspect of the case separately, divided into different units of partial analysis (embedded). Alternatively, just one unit may be used ("holistic"), when it is not possible to define partial units of analysis or the reference theory itself is holistic (Yin 1989, 2014).

The study may also involve one or multiple cases. Single-case studies are used either to analyse a case considered critical because of its importance and significance and which is valid enough to allow conclusions to be drawn (Galve and Ortega 2000; Alajoutsijärvi et al. 2001), or when one a very specific situation is to be studied (Galperin and Lituchy 1999; Min and Melachinoudis 1999; Kumar and Arora 1999; Karlsen et al. 2003; Boyett and Curie 2004; Rialp et al. 2005). The main reason for choosing to perform a multiplecase study, as well as reinforcing internal validity, is for "theoretical replication", a basic mechanism of external validation. Theoretical replication means that the experience of each case can be reproduced in others, to verify the results and identify any determining factors. This means that the causal relations of the phenomenon can be identified and any erroneous or insufficiently general ones can be eliminated. The theoretical replication used within a case study is similar to that used in multiple experiments, and the results enable logical validation of the theories (Yin 1989).

The actual number of cases that need to be studied in a multiple design should reflect the number of replications (literal and theoretical) required. This decision, therefore, is at the researchers' discretion ${ }^{2}$, and will depend on the degree of certainty they wish to obtain in their results (Rialp 1998). Logically, the greater the number of cases investigated, the greater the quality of the generalisation of the conclusions (Arias 2003).

\subsection{Design of instruments and protocols. Research methods and resources}

The research design is the logical sequence linking the empirical information to be gathered to the initial question to be researched and, ultimately, to the conclusions. In colloquial terms, it is a plan of action to be followed (Yin 1989). This plan of action requires a standardised definition of the evidence-gathering processes, to make the research more reliable and valid (Miles and Huberman 1994). To achieve this, a data-gathering protocol needs to be drawn up.

The case-study protocol should include the data-gathering instruments and also the general procedures and rules to be followed when using case study (Yin 2014). A case-study protocol is imperative in multiple-case studies, and advisable in single-case studies (Yin 2014). As a guide for action, the protocol allows researchers to clearly determine the aim of the case study and anticipate any possible problems that might arise, including any issues related to the criteria to be used for reporting the case (Arias 2003). The protocol should therefore be viewed as an instrument that will facilitate data-gathering and make it more reliable and more valid. The protocol must be dynamic, and can be altered as the case study is being conducted (Weerd-Nederhof 2001).

\footnotetext{
2 It is recommended that no less than four and no more than ten cases be used (Eisenhardt 1989). Nonetheless, single case studies may be appropriate, depending on the aims of the research (Villarreal 2008; Villarreal and Calvo 2015).
} 
The case study protocol should address certain ethical aspects, providing a list or letter informing the people involved of the approximate amount of work and time they will have to devote to the study, the activities in which they will be asked to collaborate, and how the information obtained will be dealt with, among other aspects (Miles and Huberman 1994).

The case study protocol should include the following sections (Yin 2014): a) General purpose of the case study, with general information on the context and perspective of the research (mission, objectives, and relevance of the research, general themes of the research, theoretical framework of the phenomenon analysed, proposal of the study); b) Field procedure, explaining the working procedures used in gathering information: schedule for information-gathering, obtention of permission for access to installations, arrangement of meetings, management of databases and internal documents, ensuring that there are enough sources of information and coping with possible changes in the context; c) Study issues, including the issues to be dealt with, specific aspects the researcher should take into account when gathering information and potential information sources for each question; d) Guide to the case report, specifying writing style and giving the bibliography and other documents that will aid in writing the final report.

In Yin's model (1989), the final stage in preparing for evidence gathering involves training the researchers to gather relevant information. It may be a good idea to conduct a pilot case.

\subsection{Evidence-gathering process}

The purpose of this phase is to gather any information and evidence that will help corroborate the propositions set out in the model.

With a view to defining the "facts" of the case, the proposed study should use the different sources of evidence concurrently (Rialp 1998). The different methods of collecting evidence for case studies are related to the different sources. Such sources may include: 1) documentary evidence, which includes the use of documentary information and archives (generally quantitative in nature); 2) open interviews with a range of informants; 3) direct observation, with regular "site visits" by the researcher. It may also include "participative observation", where the researcher actively interacts with the situation under observation and 4) observation of physical, technological and cultural artefacts.

The use of these sources involves different skills and methodological procedures (Fong 2002) and two basic principles must be observed in the data-gathering process:

a) Use of multiple sources of evidence. This principle makes use of triangulation ${ }^{3}$, which involves gathering and integrating evidence for each case using a variety of methods and from complementary sources of information, thus combining different methodologies to analyse the same phenomenon (Maxwell 1998; Stake 1994).

\footnotetext{
3 This process is known as triangulation or multiple operationalism (Campbell and Fiske 1959). Denzin (1984) identifies four types of triangulation: triangulation of sources, where the researcher corroborates the evidence obtained from one source using other sources; analyst triangulation, where different researchers examine the same phenomenon; theory triangulation, where the same results are obtained using different perspectives and theoretical approaches; and methods triangulation, where different methods are used to corroborate the results obtained, thus increasing the reliability of their interpretation.
} 
According to this analytical principle, a fact is considered to be firmly established when the evidence on it from three or more different sources coincides. One of the most characteristic features any case study needs to demonstrate to ensure reliability and validity, is that it is based on multiple sources of evidence (Rialp 1998).

b) Maintaining the chain of evidence : this enables other researchers to reconstruct the case, making it more reliable, by following the sequence established between the evidence, the questions to be answered by the study and the resulting conclusions. It also makes it possible to reconstruct the context in which the evidence was obtained and the criteria and techniques employed in deciding to use one sort of evidence over another.

This phase in the empirical information- gathering should ultimately make it possible to trace a line of evidence from the questions initially posed (available for review at any time) to the final conclusions of the study; it should be primarily characterised by its great instrumental flexibility to conditions that emerge during the enquiry (Rialp 1998).

\subsection{Data recording and classification}

Consists of recording and classifying the evidence gathered in a database of the case. Using the established protocol, this database should organise, integrate and summarise the information obtained from and the different sources of evidence consulted. It should be used as a prelude to facilitate analysis and ensure the general reliability of the study (Rialp 1998). A clear distinction needs to be drawn between the information from the evidence base and the research report per se. This distinction is important, because the former involves a large mass of information organised in such a way as to enable subsequent revisions, whereas the report is the result of an analysis of this base.

\subsection{Analysis of the evidence: individual analysis of each case.}

Once the data-gathering phase is complete, the next step is to analyse the evidence for each case and relate it to the established propositions. Evidence analysis is central to case study, but it is also the most complex and least coded part of a study (Fong 2002). Although evidence triangulation during the data-gathering phase is in itself a form of analytical process (Eisenhardt 1989; Maxwell 1998), most of the analysis takes place after the information has been obtained. The main aim of this phase is to process this information (inspecting, categorising, tabulating and/or recombining it), comparing it directly to the initial research propositions (Rialp 1998).

Among the recommended rules (Arias 2003), Miles and Huberman's (1984) deserve particular mention:

a) Use arrays to display the data; b) Create category matrices that allow evidence to be cross-checked; c) Create graphs aggregating the evidence; d) Tabulate frequencies for repeat behaviour and analyse these frequencies and their relations by establishing indicators such as averages and variances; e) Sort information in chronological order. 
These rules only allow the evidence to be classified and organised for operationalise the analysis (Yin 2014).

\subsection{Analysis of the evidence: overall case analysis}

The strategy recommended by Yin (2014) -which is the one most commonly used in explanatory studies (Rialp 1998) - is that after an individual analysis has been made of each case, a general analysis strategy should be employed to compare the theoretical propositions driving the study with the available evidence. This evidence is finally accepted, reformulated or rejected. The following specific systems of analysis -which determine the internal validity of the research- can be developed for this purpose (Yin 1998):

a) Pattern matching. A procedure in which an empirically-obtained pattern is matched against another pre-established one. (Trochim 1989). The theoretical pattern of behaviour expected in the dependent variables vis-a-vis the independent variables is checked against the real pattern; each new case offers an independent test of the hypothetical relations (McCutcheon and Meredith 1993). A study that includes multiple variables, in which certain initially predicted values are confirmed and alternative patterns of rival predictions are not confirmed, would offer some powerful causal inferences. However, this method cannot offer truly precise comparisons and the researcher's own interpretation is therefore fundamentally important (Rialp 1998).

b) Explanation building. Founded on the construction of the analysis using the information obtained (Yin 1982). In a single-case study -or the first case in a multiple analysis- the purpose is to see whether the information gathered converges towards a logical sequence of events that appears to explain the results of the case. In a multiple-case study designed to produce a series of replications, the tentative explanation becomes the hypothetical succession of events to be identified with the data from a second case. These may or may not confirm the proposed series, or may result in a change to the original explanation, in which case it will be necessary to go back to the first of the cases to see whether its information would support both the now-altered version and the original one. Once this has been done, the data from the third of the cases under study are analysed similarly, and so on. In itself, this iterative process constitutes a cross-analysis of the different available cases, requiring constant reference to the initial purpose and the inclusion of rival explanations.

c) Time-series analysis. This procedure is analogous to that which can be carried out in experiments or quasi-experiments. When there is a long data series for a given variable, it can be analysed using statistical tests. In this case too, the establishment of alternative or rival time patterns, together with their corresponding empirical test, helps reinforce the analysis carried out

d) Logic models. This basically consists of combining pattern matching and time-series analysis to create a model that establishes a pattern or complex chain of events over an extended period of time (time series), defining the causal relations between the variables. Data gathering will be aided by introducing measures that operate on this chain of events. The results are checked against the original model using pattern matching to determine the viability of this conceptualisation. This last option is particularly useful for making assessments based on case study research. 


\subsection{General conclusions, rigor and quality of the study, and implications of the research. Final Report}

An analysis of the evidence and comparison with the theoretical propositions brings us to the general conclusions of the study, their implications and the possibilities of extrapolating them to other contexts.

One should point out that strict observation of the methodological design we propose would maximise the validity and reliability of the results of the study. However, it is important to be aware that an investigation based on case study can never be entirely planned. The progress of the research will be conditioned by a number of variables that lie outside the researcher's control and the actual procedure may not be the same as the idealised design. It is therefore important to assess the reliability and validity of the results, in light of the way the method has actually been implemented. Following Yin (1998, 2014), Maxwell (1996) and Oltra (2003), (see Table 2), there are six tests that can be used to determine the final quality and rigor of the study: constructive validity, internal validity, external validity, reliability, theoretical/interpretative consistency and contextual consistency.

The researcher therefore needs to establish to what extent and why the method used guarantees the reliability and consistency of the research and each of the three indicators of validity listed above.

Finally, when drafting the final report of the case study, it is a good idea to set out the initial propositions and questions; the design of the study; procedures for data gathering and analysis; relations of causality; prior review of its internal validity; what has been found, the conclusions of the study and its implications; the possibility of extrapolating them to other contexts (Yin 2014) and an assessment of the quality, rigor or limitations of the study. In all cases, these should be presented in a clear structure that is appropriate to the aims of the study and the target audience. Where possible, it should also make clear and simple reading for a wider public. 
Table 2

Assessment of case study rigour and quality

\begin{tabular}{|c|c|c|}
\hline Test & Tactic & Phase of the investigation \\
\hline \multirow{10}{*}{$\begin{array}{l}\text { Constructive } \\
\text { validity }\end{array}$} & $\begin{array}{l}\text { Prior analysis of the conceptual context and } \\
\text { theoretical framework (theoretical triangula- } \\
\text { tion). }\end{array}$ & Review of the literature \\
\hline & $\begin{array}{l}\text { Structural design of main conceptual elements } \\
\text { based on the theoretical model. }\end{array}$ & Design of the research \\
\hline & $\begin{array}{l}\text { Synthesis of main explanatory factors in said } \\
\text { original model. }\end{array}$ & Design of the research \\
\hline & $\begin{array}{l}\text { Use of different methods for gathering the } \\
\text { evidence (methodological triangulation): } \\
\text { - Documentary review. } \\
\text { - Multiple in-depth interviews. } \\
\text { - Direct observation. } \\
\text { - Use of physical, technological and cultural } \\
\text { artefacts. }\end{array}$ & Evidence gathering \\
\hline & $\begin{array}{l}\text { Use of multiple sources of information. (data } \\
\text { triangulation) to confirm evidence in different } \\
\text { sources: } \\
\text { - Internal and external, direct (primary) and } \\
\text { indirect (secondary). } \\
\text { - Varied typology: documentation, files, inter- } \\
\text { views, questionnaires, databases, real physical } \\
\text { context. } \\
\text { - Diversity of key informers faced with the } \\
\text { same questions. } \\
\text { - Critical assessment of evidence compared by } \\
\text { source. }\end{array}$ & Evidence gathering \\
\hline & $\begin{array}{l}\text { Quasi-simultaneous and unified process of } \\
\text { evidence gathering and analysis. }\end{array}$ & Evidence gathering \\
\hline & Establishment of chain of evidence. & Design of the research \\
\hline & $\begin{array}{l}\text { Feedback and interactive contact with inform- } \\
\text { ers. }\end{array}$ & Gathering and analysis \\
\hline & Review of case report by key informers. & Composition \\
\hline & $\begin{array}{l}\text { General and instrumental flexibility of the } \\
\text { research through cyclical review of the field } \\
\text { study and the original structural model. }\end{array}$ & All \\
\hline \multirow[b]{2}{*}{ Internal validity } & $\begin{array}{l}\text { Common behaviour pattern (backed by theo- } \\
\text { retical propositions). }\end{array}$ & $\begin{array}{l}\text { Individual and overall } \\
\text { analysis }\end{array}$ \\
\hline & $\begin{array}{l}\text { Creation of explanation (systematic compar- } \\
\text { ison of the literature structured on the theoreti- } \\
\text { cal model). }\end{array}$ & $\begin{array}{l}\text { Individual and overall } \\
\text { analysis }\end{array}$ \\
\hline
\end{tabular}




\begin{tabular}{|c|c|c|}
\hline \multirow{7}{*}{ External validity } & $\begin{array}{l}\text { Eclectic and inclusive approach to the theoret- } \\
\text { ical perspectives and focuses. }\end{array}$ & Design of the research \\
\hline & $\begin{array}{l}\text { Use of rival theories in original model (theo- } \\
\text { retical triangulation). }\end{array}$ & General design \\
\hline & $\begin{array}{l}\text { Establishment of unit of analysis and selection of } \\
\text { cases in accordance with the potential for knowl- } \\
\text { edge concerning the phenomenon studied. }\end{array}$ & $\begin{array}{l}\text { Identification of unit of } \\
\text { analysis and selection of } \\
\text { cases }\end{array}$ \\
\hline & $\begin{array}{l}\text { Selection of evidence-gathering methods } \\
\text { (methodological triangulation) and informa- } \\
\text { tion sources (data triangulation) based on } \\
\text { the potential for knowledge concerning the } \\
\text { phenomenon under study. }\end{array}$ & $\begin{array}{l}\text { General design and evi- } \\
\text { dence gathering }\end{array}$ \\
\hline & $\begin{array}{l}\text { Use of key explanatory factors of rival theo- } \\
\text { ries in each case. }\end{array}$ & Individual analysis \\
\hline & $\begin{array}{l}\text { Application of replica logic (multiple case } \\
\text { study) to arrive at analytical generalization. }\end{array}$ & $\begin{array}{l}\text { Overall analysis and con- } \\
\text { clusions }\end{array}$ \\
\hline & $\begin{array}{l}\text { Consideration of the results of the research as } \\
\text { an initial hypothesis for studies in future lines } \\
\text { of research }\end{array}$ & $\begin{array}{l}\text { Composition and conclu- } \\
\text { sions }\end{array}$ \\
\hline \multirow{4}{*}{ Reliability } & $\begin{array}{l}\text { Creation of a study protocol and monitoring of } \\
\text { guidelines as a guide for action. }\end{array}$ & $\begin{array}{l}\text { General design and data } \\
\text { gathering }\end{array}$ \\
\hline & $\begin{array}{l}\text { Preparation of a database that will organize, } \\
\text { integrate and synthesize the information ob- } \\
\text { tained from the different sources of evidence. }\end{array}$ & $\begin{array}{l}\text { General design and data } \\
\text { gathering }\end{array}$ \\
\hline & $\begin{array}{l}\text { Ethical commitment on effort, time, dedica- } \\
\text { tion and specific activities of the key inform- } \\
\text { ers involved. }\end{array}$ & $\begin{array}{l}\text { General design and data } \\
\text { gathering }\end{array}$ \\
\hline & $\begin{array}{l}\text { Rigorous assessment of ethical aspects in } \\
\text { obtaining and analyzing the evidence. }\end{array}$ & $\begin{array}{l}\text { General design, gathering } \\
\text { and analysis }\end{array}$ \\
\hline \multirow{4}{*}{$\begin{array}{l}\text { Theoretical-inter- } \\
\text { pretative consis- } \\
\text { tency }\end{array}$} & $\begin{array}{l}\text { Prior understanding of perspectives and ter- } \\
\text { minology of the phenomenon and the context } \\
\text { according to key informers (high degree of } \\
\text { empathy with the frameworks of reference of } \\
\text { the sources of information). }\end{array}$ & $\begin{array}{l}\text { General design and data } \\
\text { gathering }\end{array}$ \\
\hline & $\begin{array}{l}\text { Use of techniques (starting protocol, open } \\
\text { questions, semi-structured interviews) that } \\
\text { will allow dialectic initiative by key inform- } \\
\text { ers. }\end{array}$ & $\begin{array}{l}\text { General design and data } \\
\text { gathering }\end{array}$ \\
\hline & $\begin{array}{l}\text { Systematic critical comparison between the } \\
\text { theoretical propositions structured in the theo- } \\
\text { retical model and those assumed and obtained } \\
\text { from the sources of evidence. }\end{array}$ & Data gathering and analysis \\
\hline & $\begin{array}{l}\text { Critical filtering of the contextual knowledge } \\
\text { based on relevant conceptual and theoretical } \\
\text { elements established in the theoretical model }\end{array}$ & Data gathering and analysis \\
\hline
\end{tabular}




\begin{tabular}{|c|c|c|}
\hline \multirow{3}{*}{$\begin{array}{c}\text { Contextual consis- } \\
\text { tency }\end{array}$} & $\begin{array}{l}\text { Attention to relevant contextual elements for } \\
\text { explaining the phenomenon to be studied, } \\
\text { even those not explicitly set out in the original } \\
\text { model. }\end{array}$ & Evidence gathering \\
\hline & $\begin{array}{l}\text { Consideration of the generic setting of the } \\
\text { units of analysis and critical assessment of the } \\
\text { evidence based on the (macro) context. }\end{array}$ & Data gathering and analysis \\
\hline & $\begin{array}{l}\text { Consideration of the specific setting of each } \\
\text { of the cases and critical assessment of the } \\
\text { evidence based on the (micro) context. }\end{array}$ & Data gathering and analysis \\
\hline
\end{tabular}

Source: Own elaboration based on Yin (1994, 2014), Maxwell (1996) and Oltra (2003).

\section{CONCLUSIONS}

In-depth case study analysis has proved to be one of the most appropriate alternative research methods for certain objectives, conditions and circumstances of an empirical study.

It has great scientific validity if the required procedures are adhered to, and can bring a level of satisfaction (thanks to the personal knowledge of the expert, wide-ranging talks of great scientific value) that is difficult to achieve with other methods.

It is especially useful when one wishes to understand a real phenomenon by looking at all the relevant variables and when ones seeks to explore or assess complex situations or phenomena.

Case study research is among the best resources for apprehending the reality of a strategic situation. It is ideally suited to research in management studies and business organisation, which involve processes such as explaining complex causal relations; analysing longitudinal processes of change; making detailed profile descriptions; creating theories or examining theoretical positions (exploratory or explanatory) using a broad, holistic and comprehensive perspective of the phenomenon under study; understanding the real context in which the phenomenon under analysis operates and in short, studying a phenomenon which is essentially complex, ambiguous and uncertain.

If it is to be used as a scientific method, it requires a rigorous prior design to ensure the greatest possible degree of validity and reliability. This should include a suitable identification of the purpose of the research; a theoretical framework of reference to guide research; proper definition of the unit of analysis; selection of a sufficient number of relevant cases; triangulation-based evidence gathering; individual and overall analysis of evidence using specific techniques (pattern matching, explanation building, comparison with the literature, etc.), presentation of the chain of evidence showing the reliability of the research and a final assessment of the rigour and quality of the study, in terms of validity and reliability.

Case study research is both useful and necessary for scientific advance in business economics. This paper seeks to offer arguments that will answer the three questions in the title in the affirmative: it is desirable, necessary and possible to perform research using case studies. 


\section{REFERENCES}

Alajoutsijärvi, K., Klint, M. and Tikannen, H., 2001. Customer relationship strategies and the smoothing of industry-specific business cycles: the case of a global fina paper industry. Industrial Marketing Management, 30, 487-497.

Angrosino, M., 2012. Etnografía y observación participante en investigación cualitativa. Madrid: Ed. Morata.

Applegate, L. M., 1994. Managing in an Information Age: Transforming the Organization for the 1990s. In: Baskerville, R., Smithson, S., Ngwenyama, O., DeGross, J.I., eds., Working Conference on Information Technology and New Emergent Forms of Organizations: Transforming Organizations with Information Technology. Amsterdam: North Holland, $15-94$.

Arias, M., 2003. Metodologías de investigación emergentes en economía de la empresa. $P a$ pers Proceedings 2003, XVII congreso nacional XIII congreso hispano-francés AEDEM. Université Montesquieu Bordeaux IV, Bordeaux, 19-28.

Beer, M., 1988. Towards a redefinition of O.D.: a critique of research focus and method, Academy of Management O.D., Newsletter Winter.

Bonache, J., 1999. El estudio de casos como estrategia de construcción teórica: características, críticas y defensas. Cuadernos de Economía y Dirección de la Empresa, 3, 123-140.

Boyett, I. and Currie, G., 2004. Middle Managers Moulding International Strategy. An Irish Start-up in Jamaican Telecoms. Long Range Planning, 37 (1), 51-66.

Campbell, D. and Fiske, D., 1959. Convergent and Discriminant Validation by the Multitrait-Multi-method Matrix. Psychological Bulletin, 56, 81-85.

Céspedes, J. J. and Sánchez, M., 1996. Tendencias y desarrollos recientes en métodos de investigación y análisis de datos en dirección de empresas. Revista Europea de Dirección y Economía de la Empresa, 5 (3), 23-40.

Cepeda, G., 2006. La calidad en los métodos de investigación cualitativa: principios de aplicación práctica para estudios de casos. Cuadernos de Economía y Dirección de la Empresa, 29, 57-82.

Cepeda, G. and Martin, D., 2005. A review of case studies publishing in management decision 2003-2004: guides and criteria for achieving quality in qualitative research. Management Decision, 43 (6), 851-876.

Cooper, H., 1984. The integrative research review. Beverly Hills, CA: Sage.

Denzin, N., 1984. The Research Act. Englewood Cliffs, NJ: Prentice Hall.

Easton, G., 1994. Methodology and industrial networks. In Wilson, D. and Moller, K., eds. Relationships and networks: Theory and Applications. Kent: PWS.

Eisenhardt, K. M., 1989. Building Theories from Case Study Research. Academy of Management Review, 14 (4), 532-550.

Eisenhardt, K. M., 1991. Better Stories and Better Constructs: The Case for Rigor and Comparative Logic. Academy of Management Review, 16, (3), 620-627.

Fong, C., 2002. Rol que juegan los activos intangibles en la construcción de ventaja competitiva sustentable en la PYME. Un estudio de casos con empresas de Cataluña y Jalisco, Tesis, (Dr). Universidad Autónoma de Barcelona, Barcelona.

Galperin, B. and Lituchy, T., 1999. The implementation of quality management in Canada and Mexico: a case study. International Business Review, 8, 323-349. 
Galve, C. and Ortega, R., 2000. Equipos de trabajo y perfomance: un análisis empírico a nivel de planta productiva. Management, 3, (4), 111-134.

Glasser, B. and Strauss A., 1967. The Discovery of Grounded Theory. Strategies for Qualitative Research. Chicago, Ill: Adine Publishing Company.

Gottschalk, L., 1968. Understanding history: A primer of historical method. New York: Knopf.

Gummesson, E., 1991. Qualitative Methods in Management Research. Newbury Park, California: Sage Publications.

Hamel, J., 1992. The case method in Sociology, Introduction: New Theoretical and Methodological Issues. Current Sociology, 40 (1), 1-7.

Hamel, J., Dufour, S. and Fortin, D., 1993. Case Study Methods, Newbury Park, California: Sage Publications.

Helmer, O., 1983. Looking Forward. Beverly Hills, California: Sage Publications.

Helmer, O. and Rescher, N., 1959. On the epistemology of inexact sciences, Management Science, 6, 25-53.

Johnston, W., Leach, M. and Liu,A., 1999. Theory testing using case studies in business-to-business research. Industrial Marketing Management, 28, 201-213.

Karlsen, T., Silseth, P. R., Benito, G. R. G. and Welch, L. S., 2003. Knowledge, internationalization of the firm and inward-outward connections. Industrial Management Marketing, 32, 385-396.

Kaufmann, A. and Gil Aluja, J., 1991. Nuevas técnicas para la dirección estratégica. Barcelona: Publicacions de la Universitat de Barcelona. 312.

Kumar, S. and Arora, S., 1999. Efficient workforce scheduling for a serial processing environment: a case study at Minneapolis Star Tribune. Omega, 27, 115-127.

Lakatos, I., 1983. La metodología de los programas de investigación científica. Madrid: Alianza Universitaria.

Landeta, J., 1999. El método Delphi. Una técnica de previsión para la incertidumbre. Barcelona: Ariel.

Martínez, P. C., 2006. El método de estudio de caso. Estrategia metodológica de la investigación científica. Pensamiento y Gestión, 20, 165-193.

Maxwell, J. A., 1996. Qualitative Research Design: An Interactive Approach. Thousand Oaks: Sage Publications.

Maxwell, J.A., 1998. Designing a Qualitative Study. In Bickman, L. and Rog, D. J., eds. Handbook of Applied Social Research Methods. Thousand Oaks: Sage Publications, 69-100.

Mccutcheon, D. and Meredith, J. R., 1993. Conducting case study research in operations management. Journal of Operations Management, 11, 239-256.

Miles, M. and Huberman, A., 1994. Qualitative Data Analysis. An Expanded Sourcebook. $2^{\mathrm{a}}$ ed., Thousand Oaks, CA: Sage.

Min, H. and Melachinoudis, E., 1999. The relocation of a hybrid manufacturing distribution facility from supply chain perspectives: a case study. Omega, 27, 75-85.

Oltra, V., 2003. Hacia la gestión del conocimiento: el papel clave de la Dirección de recursos Humanos. Una investigación empírica cualitativa. XIII Congreso ACEDE, Salamanca.

Popper, K. P., 1962. La lógica de la investigación científica. Madrid: Tecnos.

Ragin, C. and Becker, R., 1992. What is a case? Exploring the foundations of social enquiry. Cambridge: Cambridge University Press. 
Rialp, A., 1998. El método del caso como técnica de investigación y su aplicación al estudio de la función directiva. IV Taller de Metodología ACEDE, Arnedillo, La Rioja.

Rialp, A., Martínez, P. C. and Rialp, J., 2005. El Desarrollo Exportador de las PYMES Industriales Españolas Participantes en un Consorcio de Exportación: un Estudio de Caso. Cuadernos de Gestión, 5 (2), 95-116.

Rosenthal, R., 1966. Experimenter effects in behavioural research. New York: AppletonCentury-Crofts.

Ruiz, J. I., 1996. Metodología de la investigación cualitativa. Bilbao: Universidad de Deusto.

Rumelt, R. P., Schendel, D. E., and Teece, D. J., 1994. Fundamental Issues in Strategy. In Rumelt, R. P., Schendel, D. E. and Teece, D. J., eds. Fundamental Issues in Strategy: A Research Agenda. Boston, Mass: Harvard Business School Press, 9-47.

Sarabia, F. J., 1999. Metodología para la investigación en marketing y dirección de empresas. Madrid: Ed. Pirámide.

Shaw, E., 1999. A Guide to the Qualitative Research Process: Evidence from a Small Firm Study. Qualitative Market Research: An International Journal, 2 (2), 59-70.

Stake, R. E., 1994. Case Studies. In Denzin, N. K. and Lincoln, Y. S., eds. Handbook of Qualitative Research. Thousand Oaks, CA: Sage Publications, 236-247.

Stoeker, R., 1991. Evaluating and Rethinking the Case Study. The Sociological Review, 39 (1), 88-112.

Strauss, A., 1987. Qualitative Analysis of Social Science. Cambridge: Cambridge University Press.

Trochim, W., 1989. Outcome pattern matching and program theory. Evaluation and Program Planning, 12, 355-366.

Vaillant, Y., Urbano, D., Rialp, J. and Rialp, A., 2006. Un estudio cualitativo y exploratorio de cuatro nuevas empresas exportadoras. Cuadernos de Economía y Dirección de la Empresa, 29, 107-132.

Villarreal, O., 2007. La Estrategia de Internacionalización de la Empresa. Un Estudio de Casos de Multinacionales Vascas. Tesis, (Dr). Universidad del País Vasco-Euskal Herriko Unibertsitatea, Bilbao.

Villarreal, O., 2008. El caso de CIE Automotive: el crecimiento de un grupo empresarial mediante la internacionalización. Ekonomiaz, 68, 231-263.

Villarreal, O., 2011. Estudios Temáticos de Casos Innobasque "La Cooperación en la Internacionalización", Zamudio: Innobasque.

Villarreal, O. and Calvo, N., 2015. From the Triple Helix model to the Global Open Innovation model: A case study based on international cooperation for innovation in Dominican Republic. Journal of Engineering and Technology Management, 35(1), 71-92

Villarreal, O. and Landeta, J., 2010. El estudio de casos como metodología de investigación científica en dirección y economía de la empresa. Una aplicación a la internacionalización. Investigaciones Europeas de Dirección y Economía de la Empresa, 16 (3), 31-52.

Weerd-Nederhof, P., 2001. Qualitative case study research. The case of a PhD research project on organising and managing new product development systems. Management Decision, 39 (7), 513-538. 
Yin, R. K., 1982. Studying the implementation of public programs, In Williams, W., ed. Studying Implementation; Methodological and Administrative issues. Chatham, NJ: Chatham House, 36-72.

Yin, R. K., 1989. Case Study Research. Design and Methods. In Applied Social Research Methods Series 5, second edition. London: Sage Publications.

Yin, R. K., 1993. Applications of case study research. London: Sage Publications.

Yin, R. K., 1998. The Abridged Version of Case Study Research. In Bickman, L. and Rog, D. J., eds. Handbook of Applied Social Research Methods. Thousand Oaks: Sage Publications, 229-259.

Yin, R. K., 2014. Case Study Research. Design and Methods. In Applied Social Research Methods Series 5, fifth edition, Thousand Oaks: Sage Publications. 
